\title{
Struktur Kecepatan Gelombang S antara Episenter Gempa Bumi C022801L dan Stasiun Observasi KDAK dan INK melalui Analisis Seismogram
}

\author{
Bagus Jaya Santosa* \\ Jurusan Fisika, FMIPA, ITS, Jl Arif Rahman Hakim 1, Kampus ITS Sukolilo, \\ Surabaya 60111, Indonesia, Telp/Fax ++62 315943351
}

\begin{abstract}
Analisa kuantitatif atas seismogram berupa pengukuran waktu tiba gelombang S pada jarak episentral dekat adalah tidak mudah, karena gelombang S tiba dekat dan tenggelam dalam gelombang Love, sehingga penentuan waktu tiba S menjadi tidak jelas. Dalam penelitian ini struktur kecepatan S diinvestigasi melalui analisa seismogram gempa C022801L dengan seismogram sintetiknya di stasiun KDAK, Alaska dan INK, Kanada. Seismogram terukur dibandingkan terhadap sintetiknya dalam domain waktu dan ketiga komponen ruang secara simultan. Seismogram sintetik dihitung dengan program GEMINI. Input awal untuk menghitung seismogram sintetik adalah model bumi PREMAN dan solusi CMT dari gempa tersebut. Filter low-pass Butterworth dengan frekuensi sudut pada $20 \mathrm{mHz}$ dikenakan pada seismogram observasi dan sintetik. Pengamatan menunjukkan penyimpangan nyata pada waktu tempuh dan waveform beberapa fase gelombang, yaitu gelombang $\mathrm{S}$, gelombang permukaan Love dan Rayleigh dan gelombang ScS. Penelitian ini menunjukkan, bagaimana pekanya waveform terhadap struktur bumi. Penelitian ditujukan untuk menyelesaikan diskrepansi yang dijumpai pada gelombang-gelombang S, Love dan Rayleigh dan ScS, di stasiun observasi KDAK. Untuk mendapatkan pengepasan seismogram diperlukan koreksi atas struktur kecepatan $\mathrm{S}$ dalam model bumi, yaitu perubahan ketebalan kulit bumi. model kecepatan $\beta_{h}$ di upper mantle meliputi gradient kecepatan $\beta_{h}$ dan besar koefisien-koefisien order nol untuk $\beta_{h}$ dan $\beta_{v}$ atas diskrepansi pada gelombang permukaan Love dan Rayleigh. Koreksi atas penyimpangan pada gelombang S dilakukan pada sistim perlapisan bumi dari upper mantle hingga kedalaman 630 km, sedangkan untuk fase gelombang ScS koreksi dilaksanakan hingga kedalaman CMB $(2890 \mathrm{~km})$. Fitting seismogram diperoleh pada waveform berbagai fase gelombang, yaitu gelombang S, ScS dan gelombang permukaan Love dan Rayleigh, baik pada waktu tempuh osilasi utama dan jumlah osilasi, khususnya pada gelombang Love. Hasil ini menunjukkan bahwa anisotropi terjadi tidak hanya di upper mantle tetapi hingga lapisan bumi yang lebih dalam, hingga CMB.
\end{abstract}

KEYWORDS: Seismogram, Model Kecepatan S dari Upper Mantle - CMB,Waveform

\section{PENDAHULUAN}

Gempa C022801L adalah gempa kuat, terjadi pada tanggal 28 Februari 2001 di Washington, USA dengan magnitudo pada skala Richter 6.5. Akibat gempa ini seluruh isi bumi bergetar, sehingga semua tempat di permukaan bumi dapat merasakan getaran tanah akibat gempa tersebut.

Getaran / pergerakan tanah dapat diukur melalui seismometer di stasiun seismogram, diubah dari satuan kecepatan $[\mathrm{mm} / \mathrm{dt}]$ menjadi satuan tegangan listrik $(\mathrm{mV})$, direkam sebagai deret waktu dan disajikan kembali sebagai seismogram. Seismogram adalah data runtun waktu yang tersusun atas fase-fase gelombang yang kompleks, berasal dari refleksi/refraksi yang terjadi di dalam bumi, sehingga seismogram tersusun atas berbagai fase gelombang yang rumit.

Analisa kuantitatif utama pada seismogram adalah men-

${ }^{*}$ E-MAIL: bjs@physics.its.ac.id catat waktu-waktu tiba beberapa fase-fase gelombang utama, polaritas gelombang $\mathrm{P}$ dan $\mathrm{S}$. Waktu tiba yang paling mudah diamati adalah first break P. Analisa kuantitatif lain adalah mengukur kecepatan fase / group terhadap perioda / frekuensi pada gelombang permukaan, disebut sebagai analisa dispersi. Namun data pada analisa dispersi adalah hubungan antara kecepatan fase /group terhadap frekuensi dan ini adalah data sekunder.

Dari catatan atas waktu tempuh fase gelombang dapat diturunkan deskripsi tentang model-model bumi, seperti SPREM, PREMAN, Ocean [1], IASPEI91 [2] dan AK135 [3], baik model bumi global ataupun regional. Model bumi global dibentuk berdsarkan analisa rata-rata kecepatan gelombang seismik yang diperoleh dari ribuan gempa dan terekam oleh jaringan seismograf mondial. Adanya perbedaan kecepatan gelombang dari satu gempa yang tercatat di satu tasiun tentunya sudah dapat diperkirakan, lihat Katalog dari Internasional Seismological Catalog (ISC). Dari polaritas gelombang dan amplitudo dalam seismogram diturunkan deskripsi mengenai solusi CMT gempa bumi, baik lokasi hiposenter, waktu terja- 
dinya gempa dan mekanisme gempa $[4,5]$.

Himpunan data waktu tempuh yang dibentuk oleh pasangan hiposenter - stasiun-stasiun observasi atas berbagai fase gelombang dari ribuan gempa bumi, dalam waktu puluhan tahun dapat mencapai jumlah hingga jutaan data. Jumlah besar didapatkan untuk pengukuran waktu tiba gelombang P. Tetapi jumlah data untuk waktu tiba gelombang S hanya di bawah 1 $\%$ [1] dari jumlah keseluruhan data waktu tempuh. Kecilnya jumlah data waktu tempuh gelombang $\mathrm{S}$ karena sulitnya mengukur waktu tiba gelombang yang tidak datang di awal (dalam rentetan gelombang-gelombang yang kompleks) dan mengandung frekuensi rendah .

Struktur model bumi, IASPEI91, SPREM dan modelmodel bumi lanjutan dengan resolusi yang lebih rinci dari kedua model bumi standard diturunkan dari data waktu tempuh. Parameter elastik yang diperoleh dengan metoda waktu tempuh gelombang hanya kecepatan rambat gelombang $\mathrm{P}$ dan $\mathrm{S}$, dimana struktur kecepatan $\mathrm{P}$ dideskripsi dengan lebih akurat daripada struktur kecepatan S, karena jumlah datanya yang lebih banyak dan faktor kualitas data yang lebih baik. Parameter elastik yang lain, misal rapat massa, faktor kualitas redaman dan anisotropi didapatkan dengan menggunakan metoda analisa dispersi pada gelombang permukaan per komponen Kartesian, dimana dicari hubungan antara kecepatan fase/group gelombang terhadap perioda.

Dua metoda kuantitatif yang digunakan untuk menganalisa seismogram di atas hanya mengevaluasi sedikit informasi tertentu dalam sebuah deret waktu seismogram, yaitu beberapa titik dalam deret waktu seismogram. Penelitian dalam tulisan ini menggunakan metoda perbandingan seismogram terukur dan sintetik dalam domain waktu dan ketiga komponen ruang secara simultan. Masalah yang dijumpai dalam penelitian ini, apakah model-model bumi standard yang didapat dengan mengolah sedikit informasi dalam seismogram tersebut di atas dapat memberikan kembali seismogram sintetik yang menyerupai seismogram observasi, jika analisa waveform penuh dilaksanakan dengan frekuensi corner pada $20 \mathrm{mHz}$. Metoda ini adalah yang terkini $[6,7]$, karena keseluruhan informasi yang terkandung dalam seismogram akan diteliti melalui analisa waveform, bukan semata informasi-informasi tertentu dalam seismogram.

Ada banyak penelitian tentang model-model bumi di daerah riset ini, yaitu Amerika Utara, dengan resolusi yang lebih detil daripada model bumi global [8-10], dimana data utama yang dievaluasi adalah tetap data waktu tempuh gelombang dan analisa dispersi pada gelombang permukaan. Riset ini meneliti kembali model bumi di bwah sudut Barat-Utara benua Amerika Utara melalui perbandingan seismogram dalam domain waktu dan ketiga komponen secara simultan.

Seimogram sintetik dihitung dengan program GEMINI $[11,12]$, dimana inputnya adalah model bumi elastik lengkap, keterangan CMT dari gempa C022801L dan kedudukan stasiun-stasiun observasi. Guna membandingkan seimogram terukur dan sintetik dalam satuan yang sama, yaitu kecepatan $\mathrm{mm} / \mathrm{dt}$, digunakan file response dari stasiun-stasiun observasi. Data seismogram adalah milik Incorporated Research Institutions for Seismology (IRIS), dan didapat melalui hubungan internet. File response stasiun observasi melekat bersama den- gan data seismik.

Seismogram ditentukan oleh tiga faktor, yaitu model bumi, solusi CMT dan tanggap response dari sistim peralatan seismometer di stasiun observasi. Dalam riset ini solusi CMT dibiarkan, sebagaimana diumumkan oleh Univ. Harvard (http://www.seismology.harvard.edu/CMTsearch.html), tanggap response dari sistim peralatan dapat dikalibrasi. Oleh karena itu masalah yang diteliti adalah model bumi, apakah model bumi global dapat memberikan seismogram sintetik yang menyerupai sepenuhnya seismogram terukur.

\section{METODOLOGI PENELITIAN}

Data seismogram dapat diperoleh dari Databank Center IRIS, yang datanya dipesan melaui e-mail dan diambil melalui HTTP. Setiap gempa menghasilkan pergerakan tanah, yang oleh sebuah stasiun akan direkam dalam arah ketiga komponen Kartesian (N-S, E-W and vertikal Z, lokal pada kedudukan stasiun penerima, dikenal sebagai kanal rekaman dengan akhiran -E -N \&- Z). Kedudukan sumber gempa adalah di Washington, U.S.A, dengan koordinat $47.15^{0}$ lintang Utara dan $122.73^{\circ}$ bujur Barat, sedangkan stasiun pengamat KDAK terletak di $57.79^{0}$ lintang Utara dan $152.57^{\circ}$ bujur Barat dan stasiun pengamat INK terletak di $68.31^{0}$ lintang Utara dan $133.52^{0}$ bujur Barat. Untuk memisahkan komponen perge-

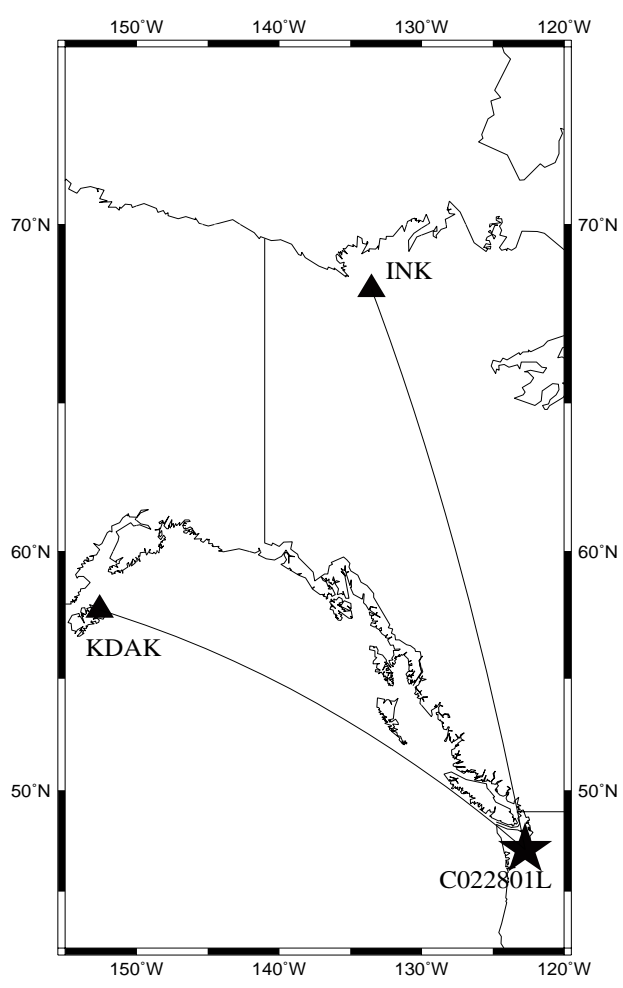

Gambar 1: Proyeksi vertikal dari sinar-sinar seismik yng dilepaskan hiposenter gempa C022801L ke stasiun observasi KDAK dan INK 
rakan tanah dalam arah toroidal dan radial, bidang horisontal yang dibentuk oleh garis N-S dan E-W lokal di stasiun observasi harus diputar, sedemikian hingga arah 'Utara' lokal diarahkan pada arah busur kecil dari stasiun observasi KDAK ke arah episenter gempa C022801L (back-azimuth), ilustrasi diberikan dalam Gambar 1. Pengubahan arah diperlukan untuk memisahkan komponen-komponen penjalaran gelombang dalam ruang 3-D menjadi mode gelombang P-SV dan SH.

Pertama dalam penelitian ini harus dijalankan program komputer untuk melaksanakan perhitungan atas waktu tempuh sintetik fase-fase gelombang ruang utama, yaitu program TTIMES yang dibuat berdasarkan makalah dari Bulland \& Chapman [13], didapat dari http://orfeus.knmi.nl. Sedangkan untuk memproduksi seismogram sintetik dari gempa tersebut di stasiun observasi digunakan program yang berbasis metoda GEMINI. Ketika program ini dijalankan, haruslah sebuah model bumi diberikan sebagai input awal, yaitu model bumi PREMAN. Sebagai model bumi masukan, data harus mengandung parameter elastik secara lengkap, yaitu meliputi kecepatan penjalaran gelombang primer dan sekunder dari batuan penyusun struktur bumi.

Metoda GEMINI adalah metoda yang ekivalen dengan metoda Sumasi Mode, dimana frekuensi batas dapat dipilih sembarang dan menghasilkan seismogram sintetik yang lengkap, dalam domain waktu dan ketiga komponen Kartesian. Program GEMINI (Green's function of the Earth by MINor Integration) adalah menghitung minor dari fungsi-fungsi Green atas suatu model bumi dan dengan suatu kedalaman sumber gempa tertentu. di mana fungsi-fungsi Green diekspansikan untuk memenuhi kondisi syarat batas di titik terdalam gelombang, titik kedalaman sumber gempa dan permukaan bumi. Ekspansi dituliskan dalam frekuensi kompleks, dengan memasukkan konstanta imaginer positif pada frekuensi, untuk menghindari time aliasing. Program DISPEC (termasuk dalam paket GEMINI) membaca posisi stasiun penerima dan parameter-parameter moment tensor, yang tertera dalam solusi CMT baris ketiga [5]. Posisi geografi episenter dan stasiun penerima ditranformasikan ke dalam koordinat pusat episenter, jarak episentral dan azimut stasiun dihitung dan diekspansikan harmonik spherif untuk stasiun penerima tersebut. Program DISPEC membaca solusi basis Green's dari GEMINI, dan membentuk sumasi atas harmonik sferis dan mengadakan transformasi balik ke koordinat geografis. Hasilnya adalah seismogram sintetik dalam kawasan frekuensi kompleks. Program MONPR, mentranform seismogram sintetik dalam frekuensi kompleks dan mengubahnya menjadi seismogram sintetik dalam domain waktu. Pada seismogram sintetik dan terukur dikenakan filter lolos rendah Butterworth pada sebuah frekuensi sudut dan RESPONSE file dari sistim peralatan seismometer di stasiun penerima dikenakan pada seismogram terukur (yang satuannya masih $\mathrm{mV}$ ), sehingga seismogram sintetik dan seismogram riil dibandingkan dalam satuan yang sama.

Jumlah data dalam komparasi seismogram pada ketiga komponen adalah ribuan, tergantung pada panjang seismogram (dengan waktu cuplik tiap satu detik, dikenal sebagai kanal Long Period) dan dikalikan ketiga komponen. Dikrepansi yang dijumpai pada perbandingan seismogram terukur dan sintetik yang dibangun dari model bumi standard begitu banyak dan ini akan diselesaikan melalui perubahan ketebalan kulit bumi, gradien kecepatan, dan besar koefisien awal fungsi polinomial kecepatan di tiap lapisan bumi, dimana perubahan dilakukan melalui metoda trial and error.

\section{ANALISA DAN PEMBAHASAN}

Dalam penelitian ditampilkan analisa sebuah gempa Washington, U.S.A., 28 Februari 2001, dengan kode C022801L, dimana gelombang seismik akibat gempa tersebut direkam oleh stasiun-stasiun observasi seismologi KDAK, Alaska dan INK, Kanada.

Gambar 2 menunjukkan perbandingan antara seismogram terukur dan sintetiknya yang dibangun dari model bumi IASPEI91 yang diletakkan di atas perbandingan seismogram terukur dengan sintetiknya dari model bumi PREMAN, di stasiun obervasi KDAK. Pada gambar ini kita melihat potonganpotongan perbandingan seimogram dalam jendela waktu gelombang S, Love dan Rayleigh dan ScS.

Gambar 2 menunjukkan analisa seismogram terukur dan sintetiknya dari gempa bumi C022801L di stasiun KDAK. Gambar 2(a) menunjukkan, bahwa pada gelombang $\mathrm{S}$ dan gelombang permukaan Love dan Rayleigh, kedua model bumi memberikan sintetik yang menyimpang jauh dari dta terukur. Model bumi IASPEI dengan ketebalan kulit bumi 35 $\mathrm{km}$ memberikan gelombang Love dengan waktu tunda yang lebih lama dan amplitudo maksimum yang juga lebih kuat daripada gelombang Love sintetik dari model bumi PREMAN dengan ketebalan kulit bumi $25 \mathrm{~km}$. Sementara waktu tiba gelombang S ditiru lebih baik oleh gelombang S sintetik dari model bumi IAESPEI91. Gelombang Rayleigh berreaksi kecil terhadap perbedan ketebalan kulit bumi ini. Gambar 2(b) menunjukkan simpangan besar pada gelombang ScS sintetik dari kedua model bumi, bahkan model bumi PREMAN memberikan simpangan yang lebih besar. Dari perbandingan seismogram pada ketiga potongan jendela waktu ini, telah jelas, bahwa analisa seimogram dengan waveform memberikan pisau yang lebih tajam untuk menganalisa seismogram. Juga dapat kita ambil tarik kesimpulan, bahwa bentuk gelombang Love sangat reaktif terhadap ketebalan kulit bumi. Hal ini belum pernah dimanfaatkan untuk riset tentang ketebalan kulit bumi.

Parameter elastik yang dimiliki oleh model bumi IAESPEI91 yang isotrop hanya dua, yaitu $\alpha$ dan $\beta$, sedangkan model bumi PREMAN lengkap dengan lima parameter elastik. Oleh karena simpangan pada gelombang permukaan Love dan Rayleigh besarannya berbeda, jelas bahwa model isotrop tidak mampu untuk menjelaskan dan menyelesaikan perbedaan simpangan secara simultan pada kedua jenis ragam gelombang permukaan. Dengan demikian untuk selanjutnya upaya dalam riset ini adalah untuk membuat pencocokan yang baik pada berbagai fase gelombang yang didasarkan pada model bumi yang diubah. Perubahan model bumi pada ketebalan kulit bumi, dan struktur kecepatan gelombang S, sedemikian hingga dicapai pengepasan yang lebih baik pada berbagai fase gelombang. 


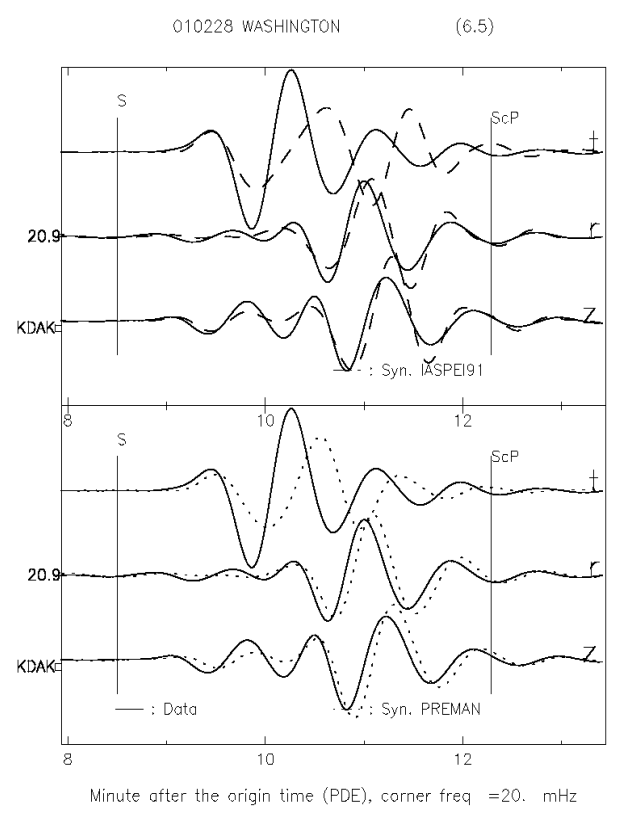

(a)Gelombang S,L \& R

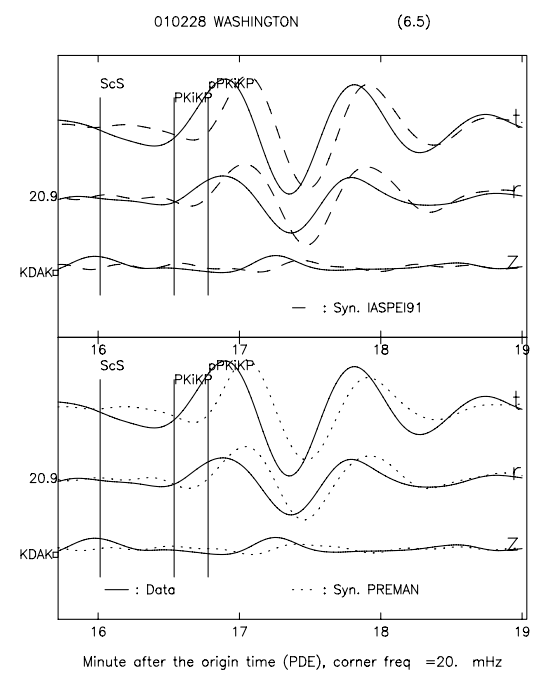

(b)Gelombang ScS

Gambar 2: Perbandingan seismogram C022801L observasi, PREMAN dan IASPEI91 di stasiun observasi KDAK

Analisa dan pengepasan seismogram di stasiun observasi KDAK disajikan dalam gambar 3. Gambar 3(a) menunjukkan perbandingan antar seismogram terukur, sintetik dari PREMAN dan model bumi dikoreksi dalam segmen waktu gelombang S, gelombang permukaan Love dan Rayleigh. Jarak dari stasiun observasi KDAK ke episenter gempa C022801L adalah $20.9^{0}$ cukup dekat, sehingga fase gelombang $\mathrm{S}$ terletak di bagian awal dari gelombang Love, dan bentuk gelombang kedua fase gelombang menjadi bersambung. Oleh karena itu pengukuran waktu tiba gelombang S pada stasiun observasi dengan jarak episentral kecil menjadi sangat sulit. Kita me-

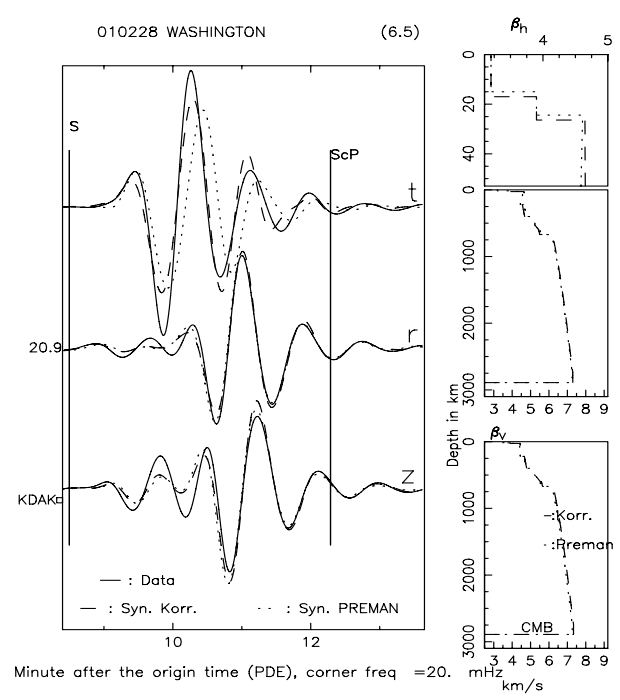

(a)Gelombang S,L \& R

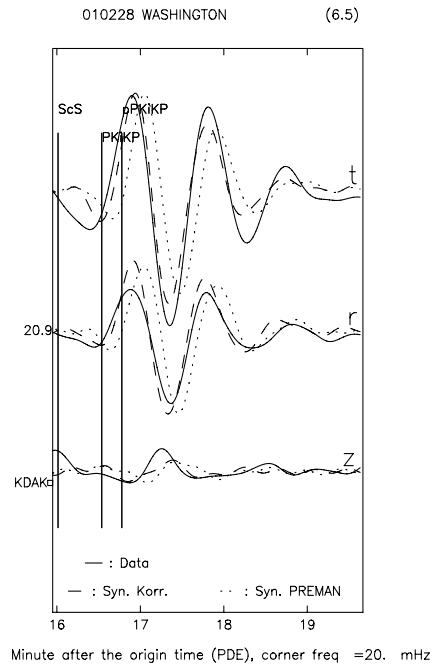

(b)Gelombang $\mathrm{ScS}$

Gambar 3: Perbandingan seismogram C022801L observasi, PREMAN dan dikoreksi di stasiun observasi KDAK

lihat bahwa gelombang S sintetik yang dihitung dari model bumi PREMAN memberikan polaritas gelombang $\mathrm{S}$ negatif (ke arah bawah), sedangkan data terukur menunjukkan polaritas yang positif, dan ini disimulasikan dengan sangat baik oleh seismogram sintetik dari model bumi dikoreksi. Target awal untuk menyelesaikan diskrepansi pertama adalah mengepaskan gelombang permukaan Love dan Rayleigh, karena gelombang ini merambat sepanjang permukaan bumi hingga suatu kedalaman yang setara dengan panjang gelombangnya, yaitu kedalaman dari dasar lapisan mantel atas. Dapat kita amati, bahwa bentuk gelombang Love dari PREMAN mem- 
punyai tiga maksimum dengan tinggi amplitudo yang setara, dan ketiga maksimum memiliki waktu tiba yang lebih dulu daripada maksimum-maksimum dalam bentuk gelombang Love terukur. Melalui metoda trial \& error, pengepasan pada gelombang Love diperoleh dengan mengubah kedalaman Moho menjadi $34 \mathrm{~km}$ dan gradien kecepatan $\mathrm{SH}\left(\beta_{h}\right)$ di lapisan mantel atas menjadi bernilai positif, bandingkan dengan gradien negatif pada model bumi PREMAN. Tentu saja koreksi kecepatan S di lapisan upper mantle harus positif, karena gelombang Love dari PREMAN datang lebih lambat daripada Love riil. Telah dicapai pencocokan yang bagus pada waktu tiba dan pola tinggi amplitudo waveform Love wave, tetapi tidak pada keseluruhan tinggi amplitudo. Kesalahan ini disebabkan tidak digunakannya perbedaan ketebalan kulit bumi, seperti telah digunakan untuk pencocokan pada gelombang Love. Semenetara pada penentuan solusi CMT sebuah gempa bumi, perbedaan ketebalan kulit bumi diandaikan dimana-mana sama [4]. Sementara pengamatan pada gelombang permukaan Rayleigh yang terdapat di komponen $\mathrm{r}$ dan z menunjukkan bahwa gelombang Rayleigh dari PREMAN mempunyai waktu tiba yang lebih awal daripada gelombang Rayleigh riil. Dengan demikian koreksi kecepatan $\beta_{v}$ harus dieksekusi pada lapisan mantel atas bernilai negatif, sehingga diperoleh fitting yang sangat baik pada bentuk gelombang Rayleigh dari model bumi dikoreksi. Fitting pada jumlah osilasi dalam gelombang $\mathrm{S}$ hingga Rayleigh sebanyak enam juga dicapai dengan baik oleh seismogram sintetik dari model kecepatan S dikoreksi.

Untuk mendapatkan fitting pada gelombang body S, struktur kecepatan $\mathrm{S}$ pada lapisan-lapisan di bawah mantel atas hingga suatu kedalaman $630 \mathrm{~km}$ harus dikoreksi dengan dengan nilai negatif, karena gelombang SH sintetik dari PREMAN juga datang lebih dulu daripada gelombang SH riil. Fitting pada gelombang Rayleigh dan juga koreksi pada kecepa$\tan \beta_{v}$ pada lapisan-lapisan hingga kedalaman $630 \mathrm{~km}$ dengan nilai negatif memberikan fitting yang sangat baik pada gelombang SV. Terlihat jumlah osilasi dari gelombang SV hingga akhir dari gelombang permukaan Rayleigh disimulasikan dengan sangat baik oleh model bumi dikoreksi.

Struktur kecepatan S di lapisan-lapisan dari kedalaman 630 $\mathrm{km}$ ke atas telah dikoreksi dengan nilai negatif untuk mendapatkan fitting yang baik, mulai dari gelombang $\mathrm{S}$ hingga gelombang permukaan Love dan Rayleigh. Koreksi negatif ini mempunyai konsekuensi untuk fitting pada waktu tiba gelombang body $\mathrm{ScS}$, yaitu gelombang $\mathrm{S}$ yang menjalar dari hiposenter ke bawah secara vertikal hingga antarmuka CMB (Core Mantle Boundary). Karena CMB merupakan reflektor yang bagus (sebagai antarmuka antara medium cair dan padat), maka gelombang ScS ini terpantul kembali ke atas dengan amplitudo yang kuat. Karena struktur kecepatan S di lapisan atas $630 \mathrm{~km}$ telah dikoreksi dengan nilai negatif, sebaliknya lapisan-lapisan mantel bawah harus dikoreksi dengan nilai positif. Gambar 3(b) menunjukkan pengepasan yang baik pada waktu tiba gelombang ScS. Jarak episentral sekali lagi adalah $20.9^{0}$, sebuah jarak yang kecil. Namun metoda perbandingan seismogram pada jendela waktu gelombang $\mathrm{ScS}$ memberikan metoda analisa yang baru untuk menyelidiki stutktur kecepatan gelombang S di daerah mantel bawah dengan stasiun observasi berjarak kecil. Bandingkan dengan riset-riset seismologi lain yang menginterpretasikan struktur mantel bawah dengan data waktu tempuh gelombang SKKS dan S, yang hanya dapat diperoleh jika stasiun-stasiun observasi memiliki jarak episentral di atas $83^{0}$ [14-16].

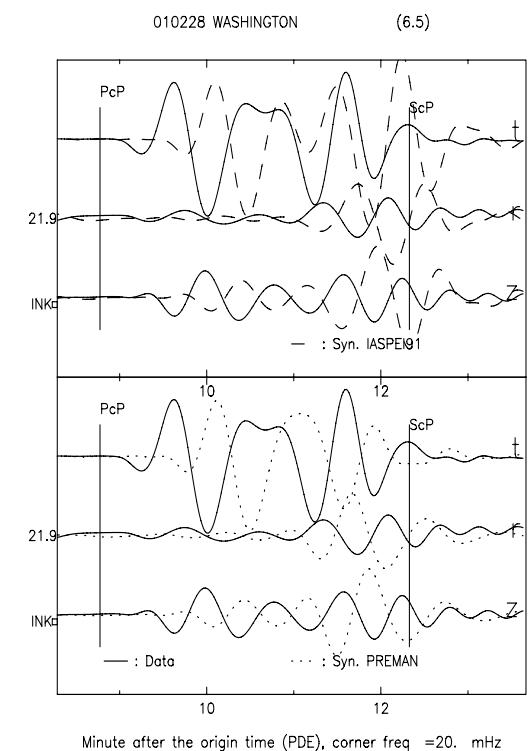

(a)S,L \& R Wave

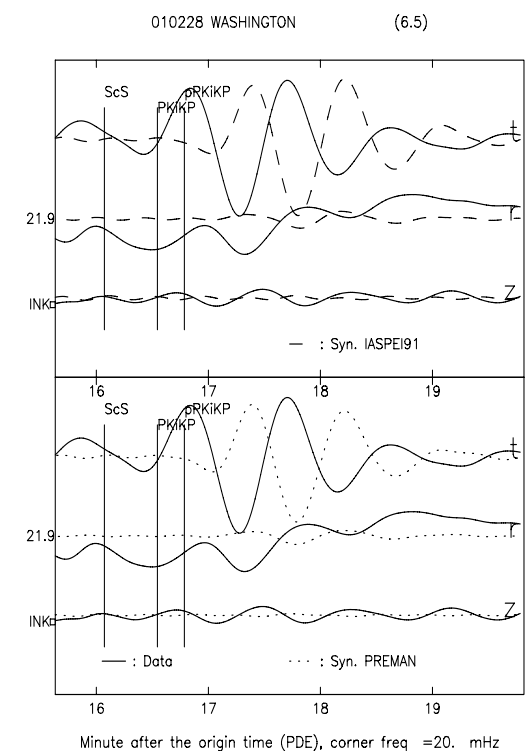

(b) ScS Wave

Gambar 4: Perbandingan seismogram C022801L di stasiun observasi INK a. Segmen waktu gelombang S, L \& R b. Gelombang ScS

Pertama kita bandingkan seismogram observasi dengan sintetiknya, yang dihitung dari model bumi PREMAN dan IAS- 
PEI91, di stasiun observasi INK, seperti diilustrasikan dalam gambar 4. Gambar 4(b) menunjukkan perbandingan seismogram untuk seegmen waktu gelombang permukaan dan $\mathrm{ScS}$. Kedua bentuk gelombang permukaan ragam Love dan Rayleigh menunjukkan penyimpangan yang sangat ramai, bahwa kedua model bumi standard memberikan gelombang permukaan yang jauh dari gelombang permukaan riil. Gelombang Love dari IASPEI91 memiliki empat maksimum seperti gelombang Love riil, sedangkan model PREMAN memberikan lima maksimum. Tetapi waktu tiba gelombang Love dari PREMAN lebih mendekati waktu tiba gelombang Love riil. Model bumi IASPEI91 mempunyai ketebalan kulit bumi 35 $\mathrm{km}$ dan gradien positif untuk $\beta_{h}$ di mantel atas, sedangkan model PREMAN $25 \mathrm{~km}$ dan mempunyai gradien negatif untuk $\beta_{h}$, dimana ketebalan kulit bumi berbeda hanya $10 \mathrm{~km}$. Dengan frekuensi sudut $20 \mathrm{mHz}$, panjang gelombang sekitar $150 \mathrm{~km}$ (ambil kecepatan rata-rata gelombang $\mathrm{S}$ dekat permukaan $3 \mathrm{~km} / \mathrm{det}$ ), ternyata kedua model ketebalan kulit bumi memberikan pengaruh yang nyata pada jumlah osilasi dalam gelombang Love [17]. Pengamatan lebih lanjut pada gelombang $\mathrm{ScS}$ terlihat $\mathrm{ScS}$ sintetik dari PREMAN terlambat 35 detik di belakang $\mathrm{ScS}$ riil.

Analisa dan pengepasan seismogram di stasiun observasi INK disajikan dalam gambar 5. Gambar 5(a) menunjukkan perbandingan seismogram antara data, sintetik dari PREMAN dan model bumi dikoreksi dalam segmen waktu gelombang primer P. Karena gelombang P sintetik dari PREMAN terlambat hingga 28 detik, koreksi atas struktur kecepatan primer berkisar hingga 3\%. Terlihat kereta waveform gelombang gelombang $\mathrm{P}$ sintetik dikoreksi lebih mendekati kereta waveform gelombang P riil. Gambar 5(b) menunjukkan pencocokan yang baik pada simulasi gelombang Love dan ScS. Terlihat, bahwa puncak maksimum kedua gelombang Love terpotong dan ini juga disimulasikan dengan baik oleh sintetik dari model dikoreksi. Pada awal dari Love wave tertera waktu tiba gelombang PcP, fase gelombang ini dapat kita lihat di komponen $\mathrm{z}$ dan $\mathrm{r}$, ternyata koreksi pada struktur kecepatan primer membawa juga perbaikan untuk simulasi gelombang PcP. Koreksi atas kecepatan rambat gelombang $\beta$ diperlukan hingga lapisan lebih bawah, hingga CMB guna mendapatkan pencocokan yang baik di fase gelombang $\mathrm{ScS}$.

Dari sini dapat kita simpulkan bahwa analisa dengan waveform pada jarak episentral yang kecil dapat memberikan pengetahuan yang lebih detil tentang struktur kecepatan S di lapisan-lapisan mantel bawah. Perhitungan atas parameter gempa, yakni solusi CMT [4], dibentuk berdasarkan pada sebuah model bumi yang standard 1066B, dimana ketebalan kulit bumi diandaikan sama pada struktur bumi global. Hal lain yang dapat kita tarik adalah, efek dari ketebalan kulit bumi terhadap tinggi amplitudo dan jumlah osilasi pada gelombang Love belum dimanfaatkan untuk penentuan moment tensor.

\section{SIMPULAN}

Struktur kecepatan S antara hiposenter gempa C022801L, Washington, USA dan stasiun observasi KDAK dan INK telah diinvestigasi melalui analisa dan pencocokan seismogram

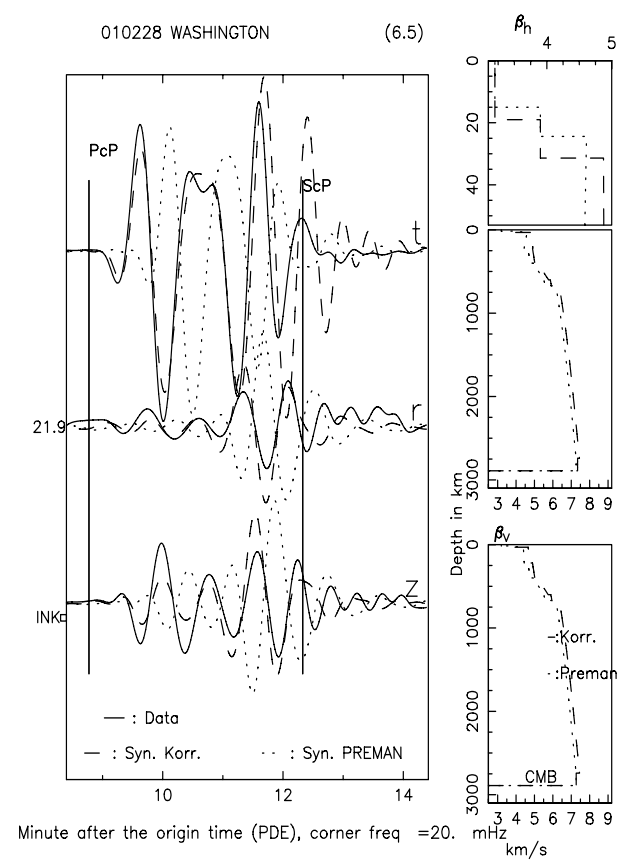

(a)S, L \& R Wave

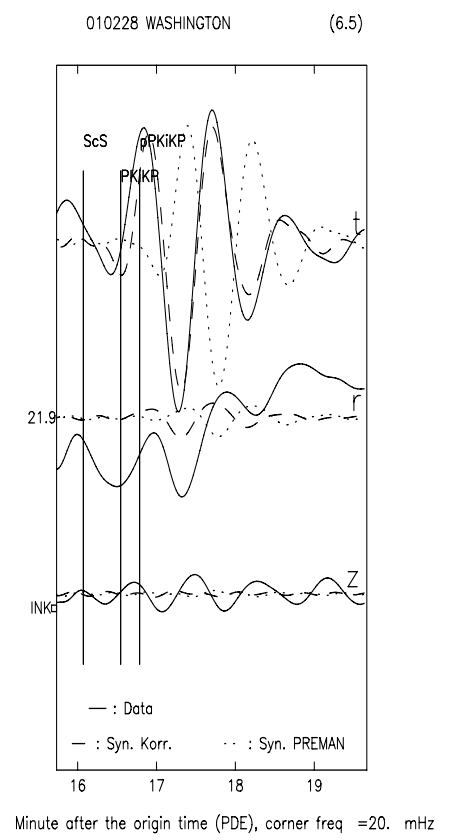

(b) ScS Wave

Gambar 5: Perbandingan seismogram C022801L observasi, PREMAN dan koreksi di stasiun observasi INK, jendela waktu a. Gelombang S, Love dan Rayleigh b. ScS 
dalam domain waktu dan tiga komponen Kartesian secara simultan, dimana pada seismogram dikenakan filter lolos rendah dengan frequensi sudut $20 \mathrm{mHz}$. Kedua daerah terletak di tepian benua (kontinental shelf), akan juga diteliti ketebalan kulit bumi di daerah ini.

Seismogram sintetik dihitung dengan program GEMINI. Input awal adalah model bumi PREMAN dan solusi CMT dari gempa tersebut.

Perbandingan antara data dan sintetiknya pada stasiun KDAK dan INK menunjukkan penyimpangan nyata pada waktu tempuh dan jumlah osilasi dalam beberapa fase gelombang, yaitu dari gelombang $\mathrm{S}$ hingga gelombang permukaan Rayleigh dan Love, dan gelombang ScS. Penelitian ini menunjukkan, bahwa bentuk gelombang ternyata bersifat sangat peka terhadap model bumi. Penelitian ini menyelesaikan penyimpangan yang ada pada gelombang-gelombang $\mathrm{S}$, Love dan Rayleigh dan ScS.

Telah dilakukan koreksi atas struktur kecepatan dalam model bumi, yaitu perubahan ketebalan kulit bumi. model kecepatan $\beta_{h}$ di mantel atas meliputi gradien kecepatan $\beta_{h}$ positif dan besar koefisien-koefisien order nol untuk $\beta_{h}$ dan $\beta_{v}$. Ini untuk menyelesaikan diskrepansi pada gelombang permukaan Love dan Rayleigh. Koreksi atas penyimpangan pada gelombang $\mathrm{S}$ dilaksanakan dengan mengubah stuktur kecepatan $\mathrm{S}$ pada sistim perlapisan bumi dari mantel atas ke bawah hingga kedalaman $630 \mathrm{~km}$. Diperoleh pengepasan yang sangat baik pada jumlah osilasi dalam bentuk gelombang, baik pada gelombang Love ataupun gelombang Rayleigh. Pengepasan terjadi dalam keseluruhan bentuk gelombang dari S hingga gelombang permukaan. Sedangkan untuk fase gelombang ScS dilaksanakan koreksi pada kecepatan S hingga kedalaman CMB.

Struktur kecepatan S 1-D dikoreksi antara episenter dan stasiun observasi, dimana koreksi dilakukan hingga kedalaman CMB. Model bumi dikoreksi menyatakan bahwa anisotropi dan heterogenitas tidak hanya terjadi di mantel atas, melainkan juga terdapat pada lapisan-lapisan yang lebih dalam. Hasil penelitian adalah model-model bumi 1-D, tetapi kedua stasiun pengamatan memerlukan model bumi yang berbeda. Ini adalah sebuah petunjuk, bagaimana kita membangun model awal untuk sebuah model bumi 3-D yang lebih detil.
[1] Dziewonski, A.M. and Anderson, D.L., Phys. of the Earth and Plan. Int., 25, 297 -356 (1981)

[2] Kennett, B.L.N., IASPEI 1991, Seismological Tables, Research School of Earths Sciences, Australian National University (1991)

[3] Kennett, B.L.N. Engdahl, E.R. \& Buland R., Geophys J Int, 122, 108-124 (1995)

[4] Dreger, D.S., Time-Domain Moment Tensor INVerse Code (TDMT_INVC), The Berkeley Seismological Laboratory (BSL), report number 8511 (2002)

[5] Dziewonski, A.M., Chou, T.A. and Woodhouse, J.H., Determination Earthquakes Source Parameters From Waveform Data for Studies of Global and Regional Seismicity, Jour. of Geophys. Res., 86, 2825-2852, (1981).

[6] Bagus J.S., Doktorarbeit, Berichte Nr. 12, Inst. fuer Geophysik, Uni. Stuttgart (1999)

[7] Gubbins, D., Seismology and Plate Tectonics, Cambridge University Press, Cambridge, 1990

[8] Frederiksen, A.W., Bostock, M.G. \& Cassidy, J.F., 2001, S- wave velocity structure of the Canadian upper mantle. Phys. of the Earth and Plan. Int., 124, 175 - 191

[9] Kennett ,B.L.N. and Gorbatov1, A., Phys. of the Earth and Plan. Int., 146, 87 - 100, 2004

[10] Zhao, D, Phys. of the Earth and Plan. Int., 146, 3 - 34 (2004)

[11] Dalkolmo, J., Diplomarbeit, Inst. fuer Geophys., Uni. Stuttgart (1993)

[12] Friederich, W. and Dalkolmo, J., Complete synthetic seismograms for a spherically symmetric earth by a numerical computation of the green's function in the frequency domain, Geophys. J. Int., 122, (537-550), (1995).

[13] Bulland, R. and Chapman, C., BSSA, 73, 1271 - 1302 (1983)

[14] Souriau, A. \& Poupinet, G., Phys. of the Earth and Plan. Int., 68, Issue 1 - 2, 183 - 199 (1991)

[15] Tanaka, S., Earth and Plan. Sci. Letters, 203, 879 - 893 (2002)

[16] Wysession, M.E., Valenzuela, R.W., Zhu, A. and Bartk, L., Phys. of the Earth and Plan. Int., 92, Issue 1 -2, 67 - 84 (1995)

[17] Bagus J.S., Majalah IPTEK 2004, Vol 15, No. 3, 1 - 6 (2004) 